\title{
Erratum to: Fetal blood flow velocimetry by phase-contrast MRI using a new triggering method and comparison with Doppler ultrasound in a sheep model: a pilot study
}

\author{
Bjoern P. Schoennagel - Chressen C. Remus • Jin Yamamura - Fabian Kording • \\ Manuela Tavares de Sousa - Kurt Hecher • Roland Fischer • Friedrich Ueberle • \\ Matthias Boehme · Gerhard Adam · Hendrik Kooijman · Ulrike Wedegaertner
}

Published online: 6 September 2013

(c) ESMRMB 2013

Erratum to: Magn Reson Mater Phy

DOI 10.1007/s10334-013-0397-0

In the original article, one of the co-author's (Manuela Tavares de Sousa) family name has been published incorrectly. The correct family name should be Tavares de Sousa.

The online version of the original article can be found under doi:10.1007/s10334-013-0397-0.

B. P. Schoennagel $(\varangle) \cdot$ C. C. Remus · J. Yamamura ·

F. Kording - M. Boehme - G. Adam - U. Wedegaertner Department of Diagnostic and Interventional Radiology, University Medical Center Hamburg-Eppendorf,

Martinistraße 52, 20246 Hamburg, Germany

e-mail: b.schoennagel@uke.uni-hamburg.de

M. Tavares de Sousa $\cdot$ K. Hecher

Department of Obstetrics and Fetal Medicine, University

Medical Center Hamburg-Eppendorf, Hamburg, Germany

R. Fischer

Department of Pediatric Hematology and Oncology, University

Medical Center Hamburg-Eppendorf, Hamburg, Germany

R. Fischer

Children`s Hospital \& Research Center Oakland,

Oakland, CA, USA

F. Ueberle

Hamburg University of Applied Sciences, Hamburg, Germany

H. Kooijman

Philips Medical Systems, Hamburg, Germany 